\title{
Farinha de inhame em massa fresca integral: avaliação da qualidade tecnológica e funcional
}

\author{
Yam flour in integral fresh pasta: technological and functional quality assessment \\ Harina de ñame en pasta fresca integral: evaluación de la calidad tecnologica y funcional
}

\author{
Andressa Rigoni Marcato \\ ORCID: https://orcid.org/0000-0003-2735-4215 \\ Universidade Estadual de Campinas, Brasil \\ E-mail: dessarigoni@gmail.com \\ Adriana Lucia Wahanik \\ ORCID: https://orcid.org/0000-0002-8999-558X \\ Universidade Estadual de Campinas, Brasil \\ E-mail: alwahanikd@gmail.com \\ Glaucia Maria Pastore \\ ORCID: https://orcid.org/0000-0001-9631-0158 \\ Universidade Estadual de Campinas, Brasil \\ E-mail: glaupast@fea.unicamp.br \\ Iramaia Angélica Neri-Numa \\ ORCID: https://orcid.org/0000-0002-2151-417X \\ Universidade Estadual de Campinas, Brasil \\ E-mail: iramaianuma@gmail.com \\ Mária Herminia Ferrari Felisberto \\ ORCID: https://orcid.org/0000-0003-1538-7941 \\ Universidade Federal de Viçosa, Brasil \\ E-mail: maria.felisberto@ufv.br \\ Pedro H. Campelo \\ ORCID: https://orcid.org/0000-0002-5137-0162 \\ Universidade Federal do Amazonas, Brasil \\ E-mail: pedrocampelo@ufam.edu.br \\ Maria Teresa Pedrosa Silva Clerici \\ ORCID: https://orcid.org/0000-0002-8445-336X \\ Universidade Estadual de Campinas, Brasil \\ E-mail: mclerici@unicamp.br
}

\begin{abstract}
Resumo
Este trabalho visou avaliar a influência da adição de farinha de inhame (Disocorea ssp.) sobre a coloração de massas frescas, assim como seus efeitos na qualidade das mesmas, além de propor também um maior valor agregado ao inhame, objetivando diminuir sua perda no agronegócio brasileiro, viabilizando maiores possibilidades de uso para esse tubérculo e promovendo a agricultura familiar. Foram produzidas quatro formulações de massa integral fresca:massa controle (M0), contendo $51 \%$ farinha de trigo de grão inteiro (FIT) e $49 \%$ de farinha refinada de trigo (FRT), e nas demais massas, a FRT foi substituída pela farinha de inhame nos níveis de 5, 10 e 15\% (M1, M2 e M3, respectivamente). $\mathrm{O}$ aumento percentual da substituição por farinha de inhame (FI) acarretou em uma menor umidade da massa e rendimento, com aumento da dureza e da perda de sólidos durante o cozimento, sendo a M3 aquela que se diferiu estatisticamente da massa controle. A M2 foi selecionada para avaliar comparativamente a capacidade antioxidante com MO, por os parâmetros de qualidade mais próximos a ela. M2 apresentou maiores valores de ABTS e DPPH em relação à M0, sendo que não diferiram no teor de fenólicos totais $(0,28 \mu \mathrm{g}$ ácido gálico equivalente/mg de amostra seca). A farinha de inhame apresentou potencial promissor para uso em massas integrais, tanto tecnológicos quanto funcionais, o que pode ser benéfico para o aumentar o valor agregado deste tubérculo.
\end{abstract}

Palavras-chave: Agronegócio; Inhame; Farinha de trigo integral; Massa fresca; Saudabilidade.

\section{Abstract}

This work aimed to evaluate the influence of the addition of yam flour (Disocorea ssp.) on the color of fresh pasta, as well as its effects on their quality, in addition to proposing a greater added value to the yam, aiming to reduce its loss in Brazilian agribusiness, enabling greater possibilities of use for this tuber and promoting family farming. Four formulations of fresh wholegrain pasta were produced: control pasta (M0), containing $51 \%$ whole grain wheat flour (FIT) and 49\% refined wheat flour (FRT), and in the other pasta, FB was replaced by flour at levels of 5, 10 and $15 \%$ (M1, M2 and M3, respectively). The percentage increase in substitution for yam flour (FI) resulted in lower dough moisture, with M3 being the one that differed statistically from the control dough. Regarding the firmness of raw pasta, 
the increase in HR increased the hardness of whole pasta, decreased the yield and increased the loss of solids during cooking. M2 was the one that presented quality parameters closest to M0 and was selected to evaluate the antioxidant capacity comparatively with M0. M2 showed higher values of ABTS and DPPH in relation to M0, and they did not differ in the total phenolic content $(0.28 \mu \mathrm{g}$ gallic acid equivalent $/ \mathrm{mg}$ of dry sample). Yam flour showed a promising potential for use in whole pasta, both technological and functional, which can be beneficial to increase the added value of this tuber.

Keywords: Agribusiness; Yams; Whole wheat flour; Fresh pasta; Healthiness.

\section{Resumen}

Este trabajo tuvo como objetivo evaluar la influencia de la adición de harina de ñame (Disocorea ssp.) en la coloración de pastas frescas, así como sus efectos en la calidad de las mismas, además de proponer un mayor valor agregado al ñame, a fin de disminuir su perdida en el agronegocio brasileño, permitiendo mayores posibilidades de uso para este tubérculo y promoviendo la agricultura familiar. Fueron producidas cuatro formulaciones de pasta fresca integral: la pasta control (M0), que contuvo 51\% de harina de trigo integral (FIT) y $49 \%$ de harina de trigo refinada (FRT), y las demás pastas, donde la FRT fue sustituida por la harina de ñame en niveles de 5, 10 y 15\% (M1, M2 y M3, respectivamente). El aumento porcentual de la sustitución por la harina de ñame (FI) resultó en masas con menor humedad y rendimiento, siendo M3 la que presentó diferencias estadísticas la masa control. En cuanto a la firmeza de la pasta cruda, el aumento de FI incrementó la dureza de la pasta integral, disminuyó su rendimiento y aumentó la perdida de sólidos durante su cocción. M2 fue la única que presentó parámetros de calidad cercanos a M0, por lo que fue seleccionada para comprar su capacidad antioxidante con el control. M2 presentó mayores valores de ABTS y DPPH en relación con M0, sin embargo, no difirieron en el contenido de fenólicos totales $(0.28 \mu \mathrm{g}$ acido gálico equivalente/mg de muestra seca). La harina de ñame demostró tener potencial, tanto tecnológico como funcional, para ser utilizado en elaboración de pastas integrales, lo que puede ser beneficioso para aumentar el valor agregado de este tubérculo.

Palabras clave: Agronegocio; Name; Harina integral de trigo; Pasta fresca; Salubridad.

\section{Introdução}

A pandemia do COVID-19 trouxe um alerta para as economias mundiais, principalmente em relação a cadeia produtiva de alimentos. Em tempos de crise, países costumam a fechar suas economias, principalmente o comércio de alimentos, a fim de garantir o abastecimento interno de sua população (Hobbs, 2020; Hoover, 2020). Outro problema grave em relação ao comércio de alimentos em tempos de pandemia é o risco sanitário relacionados ao transporte destes suprimentos já que há possibilidade dos alimentos, embalagens e outros equipamentos estarem contaminados, oferecendo riscos à saúde da população local (Laborde et al., 2020).

Uma boa alternativa para redução dos problemas relativos a comercialização de alimentos em tempos de crises sanitárias é o uso sustentável de matérias-primas locais que ao mesmo tempo que reduzem a dependência de alimentos externos favorece o desenvolvimento das comunidades locais, gerando emprego e renda para diversas famílias (Amorim et al., 2020; Schneider et al., 2020).

A obesidade, a desnutrição, as dislipidemias, hipertensão, diabetes, cardiopatias, dentre outras, além da diminuição qualidade de vida da população, estão intimamente ligadas à alimentação do indivíduo e a mudança na alimentação pela qual a sociedade tem passado é caracterizada por uma dieta extremamente calórica, rica em açúcares e gorduras, e insatisfatória quanto ao aporte nutricional, revelando as consequências que uma alimentação sem qualidade pode trazer do ponto de vista da saúde. (França et al., 2002).

O inhame (Dioscorea ssp.) é um tubérculo que está amplamente difundido pelo mundo, com maior predominância na zona tropical do planeta. O inhame é uma planta monocotiledônea, herbácea, trepadeira, de clima tropical e subtropical. Seus tubérculos são ricos em carboidratos e vitaminas do complexo B, além de encerrar teores das vitaminas A e C (Leonel et al., 2006).

O inhame é pouco utilizado na culinária brasileira devido sua produção sazonal e dificuldade no armazenamento, limitando o seu uso. Entretanto, a transformação desse tubérculo em farinha facilitaria seu manuseio e transporte, permitindo disponibilidade para consumo regular, além de ofertar ao mercado o produto de forma atrativa e conveniente para diversos preparos culinários (Siqueira, 2011). 
O uso de novos ingredientes além de ser uma alternativa de diversificação da dieta pode ser uma alternativa de incorporação de outras substâncias que podem melhorar as características físico-químicas, a aceitação sensorial e a saudabilidade de pastas. Exemplos já estudados podem ser citados como o uso de farinha de quinoa (Demir \& Bilgiçli, 2020), beterraba, espinafre e abóbora (Vimercati et al., 2020), resíduos de soja (Quinaud et al., 2020) e farinha de mariscos (Monteiro et al., 2020).

Com isso, o objetivo deste trabalho foi avaliar o uso de farinha de inhame em massa fresca produzida com farinha integral e farinha refinada de trigo, como alternativa para aumentar a aceitação visual e de sabor do produto, além de promover maior uso deste tubérculo pelo agronegócio.

\section{Metodologia}

\subsection{Materiais}

Utilizou-se farinha refinada de trigo obtida diretamente do comércio e inhame obtido no mercado local de Campinas, ambos de um mesmo lote. O grão de trigo (Triticum aestivum) obtido de um cultivar de um único lote e foi moído em moinho experimental (Quadrumat Senior, Brabender-Germany) para produção da farinha integral de trigo, que foi usado para o desenvolvimento das massas frescas. Todos os reagentes para análises foram de grau analítico.

\subsection{Processamento da farinha de inhame}

Os inhames foram lavados em água corrente para retirada das sujidades aparentes. Após, os tubérculos foram sanitizados em solução de cloro 200 ppm por 20 minutos e em seguida enxaguados com água filtrada para retirada do cloro remanescente. Os tubérculos foram descascados e cortados em fatias de 2 a $3 \mathrm{~mm}$ de espessura e branqueados em água quente para inativação da peroxidase (verificado com teste do guaiacol). Posteriormente, as amostras foram secas em estufa com circulação de ar forçado a $57{ }^{\circ} \mathrm{C}$ por 12 horas até obtenção do teor de umidade final inferior a $10 \%$. O material seco foi moído usando moinho de facas para a obtenção da farinha(Donado-Pestana et al., 2012).

\subsection{Processamento da farinha de trigo de grão inteiro}

Os grãos de trigo foram selecionados e separados manualmente. Após, determinou-se a umidade do grão utilizando infravermelho e foi feita a correção do teor de umidade para 15\% utilizando água filtrada para melhor rendimento na moagem do grão. O trigo foi então moído em moinho experimental (Quadrumat Senior, Brabender-Germany) e o farelo e germe resultantes foram moídos no moinho de bancada (Tecnal) para diminuição da granulometria. Após todas estas etapas de moagem, todas as partes foram misturadas e homogeneizadas para obtenção da farinha de grão inteiro de trigo.

\subsection{Caracterização físico-química das farinhas}

Realizou-se a composição centesimal das farinhas, segundo os teores de umidade, proteína, cinzas e lipídeos(AACCI, 2010), sendo o teor de carboidratos totais calculados por diferença.

\subsection{Características reológicas das farinhas}

As farinhas utilizadas no projeto foram caracterizadas por farinografia e extensografia (AACCI, 2010). Os parâmetros avaliados foram: R, que representa a resistência que a massa apresenta à extensão após 5 minutos do início do estiramento; RM, que representa a resistência máxima da massa à extensão; E, de extensibilidade, que representa o quanto a massa pode ser esticada sem que se rompa; A: que representa a energia exercida e R/E: número proporcional que representa a relação entre a resistência à extensão e a extensibilidade. 
Foram produzidas quatro formulações (M0, M1, M2 e M3) de massa fresca, conforme Tabela 1. O processo de produção das massas frescas consistiu em misturar os ingredientes com água filtrada, cujo teor de adição foi determinado de acordo com a umidade das farinhas (aproximadamente $42 \%$ de água) em uma Pastaia (Italvisa/SP) por 20 minutos, após, deixou-se a massa descansar por 5 minutos e então misturou por mais 2 minutos para posterior extrusão a frio da massa fresca tipo Spaguetti, trefila de $1,8 \mathrm{~mm}$. Ao mesmo tempo em que a massa ia saindo da matriz, a mesma era submetida a uma rápida secagem com ventilação forçada. Após a produção, as massas foram colocadas em sacos de polietileno, seladas hermeticamente e armazenadas sob refrigeração até realização das análises.

Tabela 1. Formulações das massas frescas com farinha integral e com substituição parcial da farinha refinada por farinha de inhame (em \%).

\begin{tabular}{cccc}
\hline Formulações & Farinha de Inhame & Farinha refinada de trigo & Farinha de trigo integral \\
\hline M0 & 0 & 49 & 51 \\
M1 & 5 & 44 & 51 \\
M2 & 10 & 39 & 51 \\
M3 & 15 & 34 & 51 \\
\hline
\end{tabular}

Fonte: Autores.

Análises da massa fresca:

- Teor de umidade, segundo o método nº44-15A (AACCI, 2010)

- Teste de cozimento (método nº 16-50), rendimento de cozimento ( $\left.{ }^{\circ}{ }^{\circ} 16-50\right)$ e teor de sólidos na água de cozimento $\left(n^{\circ} 16-50\right)(A A C C I, 2010)$;

- Textura, que foi medida por meio do aparelho Texturômetro (AnalyzerTA.XT2, Stable Micro Systems,England) e probe Light Knife Blade (A/LKBF), específico para macarrões. Foram obtidos os resultados de firmeza e força para cortar;

- Cor, realizada em Colorímetro (Miniscan XE 3500 Hunterlab, USA) pelo sistema CIE-Lab, medindo os valores $L^{*}, a^{*}, b^{*}$ o $\Delta E^{*}$.

Após a avaliação das características tecnológicas, foi feita a seleção da massa com inhame que apresentou resultados de tempo de cozimento, rendimento, perda de sólidos e textura próximos à massa $\mathrm{M} 0$, por meio do teste de Tukey ( $<0,05)$, para análise da capacidade antioxidante.

\subsection{Capacidade antioxidante}

Para avaliar a capacidade antioxidante foram selecionadas a formulação M0 e a que apresentasse características tecnológicas semelhantes a ela, com exceção da cor. Inicialmente as amostras de espaguete utilizadas para a determinação da capacidade antioxidante foram ultracongeladas em freezer, liofilizadas e por fim foram moídas em moinho de bolas. As formulações M0 e M2 foram analisadas segundo as metodologias de Folin-Ciocalteu (Fenólicos Totais), DPPH (sequestro de radicais livres) e ABTS (cátion radical). Todas as análises foram desenvolvidas com uma amostra obtida a partir da massa fresca tipo espaguete ultracongelado, liofilizado e moído, com a adição de metanol resultando em uma concentração de $0,5 \mathrm{mg} / \mathrm{mL}, \mathrm{o}$ extrato de massa fresca.

A quantificação de compostos fenólicos totais foi realizada usando o método Folin-Ciocalteu (Roesler et al., 2007). Cada amostra de formulação de pasta foi ultra congelada, liofilizada, moída e dissolvida em metanol para se obter uma solução 
de extrato de pastas de $0,5 \mathrm{mg} / \mathrm{mL}$. Uma alíquota de $200 \mathrm{ul}$ de extrato de pasta foi centrifugada a $4900 \mathrm{rpm}$ durante 5 min (Baby I - BL 206, Fanem - São Paulo, Brasil) e misturadas com 1000 mL de reagente de Folin - Ciocalteau 10 vezes diluído e 800 uL de solução de sódio carbonato 7,5\%. Após 5 min a $50^{\circ} \mathrm{C}$, a absorbância foi lida a $760 \mathrm{~nm}$ no espectrofotómetro (DU - 640 TM, Beckamn - Coulter - Brea, CA, EUA) . As concentrações padrões de ácido gálico (0,3125-50 mg / mL) foram usados para preparar uma curva de calibração e os resultados foram expressos como miligramas de equivalentes de ácido gálico (GAE mg/g de massa seca). Estimativa dos compostos fenólicos foi realizado em triplicata obtendo-se a média.

A capacidade de eliminação do radical cátion ABTS foi medida utilizando o método espectrofotometrico(Re et al., 1999). O ABTS foi dissolvido em água a uma concentração de $7 \mathrm{mM}$. ABTS radical catiônico (ABTS •) foi produzido por reação de solução de estoque de ABTS com persulfato de potássio 2,45 mM (concentração final) e deixando a mistura em repouso no escuro à temperatura ambiente de 12-16 h antes da utilização. Uma alíquota de $2 \mathrm{ml}$ desta solução foi diluída em $100 \mathrm{~mL}$ de etanol, e ajustada por diluição/concentração para uma absorbância de 0,70 $\pm 0,02$ a 734 nm.

A curva padrão de Trolox foi preparada por adição de $1000 \mu \mathrm{L}$ de solução diluída de ABTS • a $200 \mu \mathrm{L}$ de padrões

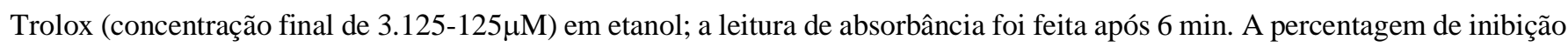
da absorbância a $734 \mathrm{~nm}$ foi calculada e representada graficamente como uma função da concentração de Trolox. Da mesma forma, uma alíquota de $25 \mathrm{uL}$ de extrato de pasta (preparada tal como no item 1.1) e $175 \mathrm{uL}$ de etanol foram misturados com $1000 \mathrm{~mL}$ de solução diluída de ABTS. Depois de 6 minutos de reação, a absorbância do ABTS remanescente foi medida a 734 $\mathrm{nm}$ utilizando-se um branco. Os resultados foram expressos em $\mu \mathrm{g}$ de Trolox equivalente (TE)/g de amostra seca.

A atividade eliminadora de radical livre foi medida utilizando um método adaptado (Brand-Williams et al., 1995). A solução de DPPH (0,004 \% w/v) foi preparada em metanol e, em seguida, armazenadas sob refrigeração até serem utilizadas. A absorbância foi medida e ajustada para 1,0 0,2 a $517 \mathrm{~nm}$, utilizando o espectrofotómetro. Uma curva padrão foi construída com Trolox variando entre 25 e $200 \mu \mathrm{M}$. Uma alíquota de 100 ul de extrato de massa (preparado como nos fenóis totais) e $100 \mathrm{~mL}$ de metanol foram misturadas com $1000 \mathrm{~mL}$ de solução de DPPH. Após 30 minutos de reação no escuro, a absorbância do DPPH remanescente foi medida a $517 \mathrm{~nm}$ utilizando-se um branco. Os resultados foram expressos em equivalente Trolox $\mu \mathrm{g}$ (TE). $\mathrm{g}^{-1}$ de matéria seca.

\subsection{Análise estatística}

Os dados foram avaliados por meio da análise de variância (ANOVA) ao nível de significância de 5 \%, e a diferença entre as médias dos resultados foi avaliada pelo Teste de Tukey (p-valor< 0,05) para comparação de médias, utilizando o programa estatístico SAS, versão 9.4, licenciado pela UNICAMP.

\section{Resultados e Discussão}

\subsection{Caracterização das farinhas}

Na Tabela 2 estão apresentados os resultados obtidos na avaliação da composição centesimal das farinhas de inhame, de trigo de grão inteiro e de trigo refinada. A farinha de trigo é o principal produto do trigo, sendo utilizada como o ingrediente principal da maioria das massas em geral, assim ter o controle de sua qualidade é de extrema importância. No Brasil, os parâmetros de identidade e qualidade da farinha de trigo são estabelecidos por regulamento técnico, através da Instrução Normativa $\mathrm{n}^{\circ} 38$ do Ministério da Agricultura, Pecuária e Abastecimento, de 30 de Novembro de 2010, denominada "Regulamento Técnico do Trigo" (Brasil, 2010). Este regulamento conceitua e define os tipos de farinha e os limites permitidos para a mesma. Segundo essa legislação, a farinha de trigo utilizada em nosso trabalho é do tipo 1 e está dentro da norma vigente, pois está dentro dos parâmetros de teor máximo de cinzas de $0,8 \%$ e teor de proteína superior à $8 \%$ (ambos expressos em base 
seca), bem como a umidade máxima de 15\%, conforme pode ser visto na Tabela 2.

Tabela 2. Composição centesimal das farinhas refinada (FRT), integral (FIT) e de inhame (FI).

\begin{tabular}{cccc}
\hline Parâmetros & FRT & FIT & FI \\
\hline Umidade (\%) & $11,59 \pm 0,17 \mathrm{~b}$ & $13,25 \pm 0,17 \mathrm{a}$ & $8,35 \pm 0,07 \mathrm{c}$ \\
Proteínas (\%) & $8,05 \pm 0,21 \mathrm{c}$ & $12,56 \pm 0,25 \mathrm{~b}$ & $14,38 \pm 0,11 \mathrm{a}$ \\
Cinzas (\%) & $0,61 \pm 0,02 \mathrm{c}$ & $1,36 \pm 0,10 \mathrm{~b}$ & $2,74 \pm 0,16 \mathrm{a}$ \\
Lipídios (\%) & $0,39 \pm 0,29 \mathrm{~b}$ & $1,92 \pm 0,34 \mathrm{a}$ & $1,48 \pm 0,08 \mathrm{a}$ \\
Carboidratos (\%) & $79,36 \pm 1,25 \mathrm{a}$ & $70,91 \pm 2,33 \mathrm{~b}$ & $73,05 \pm 2,9 \mathrm{~b}$ \\
\hline
\end{tabular}

Os dados são apresentados como média \pm desvio padrão. ${ }^{\mathrm{a}-\mathrm{c}}$ letras iguais na mesma coluna não diferem significativamente (p-valor $\left.>0,05\right)$ pelo teste de Duncan. Fonte: Autores.

Voltando a norma "Regulamento Técnico de Identidade e Qualidade da Farinha de Trigo", esta define Farinha de Trigo Integral como o produto elaborado com grãos de trigo (Triticum aestivum L.) ou outras espécies de trigo do gênero Triticum, ou combinações por meio de trituração ou moagem e outras tecnologias ou processos a partir do processamento completo do grão limpo contendo ou não gérmen (Brasil, 2005). A partir dessa norma é possível observar que a farinha de trigo de grão inteiro utilizada no trabalho se encontra dentro da legislação, pois apresenta parâmetros dentro daqueles permitidos, que são teor máximo de cinzas de 2,5\% e teor mínimo de proteínas de $8 \%$ (ambos expressos em base seca), bem como umidade máxima de $15 \%$.

$\mathrm{O}$ inhame é fonte de energia, sendo composto principalmente de carboidratos amiláceos e fibras dietéticas solúveis. Juntos, eles elevam os níveis de açúcar no sangue de forma lenta se comparado aos açúcares simples e, portanto, pode ter baixo índice glicêmico(Siqueira, 2011). A partir da Tabela 2, é possível observar o alto valor de carboidratos,que condiz com a literatura.Este tubérculo é uma excelente fonte de grupo do complexo B de vitaminas. Ele fornece necessidades diárias adequadas de piridoxina (vitamina B6), tiamina (vitamina B1), riboflavina, ácido fólico, niacina e ácido pantatênico. Essas vitaminas facilitam várias funções metabólicas no organismo.

Na Tabela 3 estão representadas as características extensográficas das farinhas de trigo refinada e de grão inteiro. Os extensogramas foram obtidos após 45, 90 e 135 minutos, o que permite avaliar as propriedades de extensão da massa durante a fermentação. A avaliação reológica da farinha é de extrema importância para a indústria, pois ajuda a predizer as características de processamento da massa e a qualidade dos produtos finais. Além disso, a reologia desempenha papel importante no controle de qualidade. Entre as determinações disponíveis para avaliar as propriedades da massa e definir o uso final da farinha de trigo, incluem-se as características de mistura (farinógrafo) e características de extensão (extensógrafo). 
Tabela 3. Propriedades reológicas (extensografia e farinografia) das farinhas de trigo refinada e de grão inteiro.

\begin{tabular}{|c|c|c|c|}
\hline Parâmetros Extensógrafo & Tempo (min) & Farinha de trigo refinada & $\begin{array}{c}\text { Farinha de trigo de grão } \\
\text { inteiro }\end{array}$ \\
\hline \multirow{3}{*}{ Energia (A) } & 45 & 141 & 58,5 \\
\hline & 90 & 146 & 59 \\
\hline & 135 & 140 & 57,5 \\
\hline \multirow{3}{*}{$\mathrm{R}(\mathrm{UE})$} & 45 & 306,5 & 343 \\
\hline & 90 & 370,5 & 373,5 \\
\hline & 135 & 345,5 & 354,5 \\
\hline \multirow{3}{*}{$\mathrm{E}(\mathrm{min})$} & 45 & 208,5 & 113,5 \\
\hline & 90 & 190,5 & 107,5 \\
\hline & 135 & 193,5 & 110 \\
\hline \multirow{3}{*}{ RM (UE) } & 45 & 497,5 & 343,5 \\
\hline & 90 & 564 & 373,5 \\
\hline & 135 & 537,5 & 354,5 \\
\hline \multirow{3}{*}{$\mathrm{D}(\mathrm{UE} / \mathrm{min})$} & 45 & 1,45 & 3,05 \\
\hline & 90 & 1,95 & 3,45 \\
\hline & 135 & 2,3 & 3,2 \\
\hline \multirow{3}{*}{ Número ratio (máx) } & 45 & 2,4 & 3,05 \\
\hline & 90 & 2,95 & 3,45 \\
\hline & 135 & 2,8 & 3,2 \\
\hline \multicolumn{2}{|c|}{ Parâmetros Farinógrafo } & Farinha de trigo refinada & $\begin{array}{c}\text { Farinha de trigo de grão } \\
\text { inteiro }\end{array}$ \\
\hline \multicolumn{2}{|c|}{ Absorção de água (\%) } & 61,1 & 65,1 \\
\hline \multicolumn{2}{|c|}{ Tempo de chegada (min) } & 1,69 & 3,08 \\
\hline \multicolumn{2}{|c|}{ Tempo de desenvolvimento de massa (min) } & 9,71 & 7,04 \\
\hline \multicolumn{2}{|c|}{ Tempo de saída (min) } & 26,24 & 13,41 \\
\hline \multicolumn{2}{|c|}{ Estabilidade (min) } & 24,56 & 10,33 \\
\hline \multicolumn{2}{|c|}{ Índice de tolerância à mistura (U.F.) } & 20,67 & 37,33 \\
\hline
\end{tabular}

EU: unidades extensográficas, R: resistência à extensão ou elasticidade, RM: resistência máxima, E:extensibilidade e D: número proporciona. Fonte: Autores.

O farinograma avalia as características de mistura e hidratação da farinha, o desenvolvimento do glúten e a estabilidade da massa à mistura (AACCI, 2010). Este instrumento simula o processo de mistura, medindo e registrando a resistência de uma massa durante os sucessivos estágios de seu desenvolvimento. A partir desse aparelho são obtidos os dados de absorção de água (ABS) em \%, tempo de desenvolvimento da massa (TDM) em min, estabilidade ou o tempo que a massa permanece consistente durante o batimento (500 UF) em minutos e o índice de tolerância à mistura (ITM) que é medido em UF após um intervalo de cinco minutos do ponto de consistência máxima da massa. Segundo Pizzinato, (1999), os parâmetros de qualidade obtidos para a farinha de trigo utilizada a classificam como forte/muito forte por apresentar ABS maior que 58\%, TDM próximo a 10 minutos e estabilidade maior que 15 minutos, parâmetros que a classificam como muito forte e ITM entre 15 e 50 que a classifica como forte. 
A farinha de trigo também pode ser classificada como forte em relação à resistência de sua proteína já que apresentou alta absorção de água, tempo de desenvolvimento da massa elevado (maior que 15 minutos) e certa tolerância ao excesso de mistura (Pizzinato, 1999). Foi possível observar que a farinha de trigo refinada é mais forte que a farinha de trigo de grão inteiro, evidenciando uma boa qualidade da rede de glúten. Para produção de massas, o uso da farinha de grão inteiro e adição de farinha de inhame podem diminuir a extensibilidade, melhorando a qualidade da farinha para produção de espaguete.

O extensógrafo foi desenvolvido para completar as informações fornecidas pelo farinógrafo, medindo e registrando a resistência da massa à extensão e extensibilidade, enquanto ela é esticada sob velocidade constante até seu rompimento (Pizzinato, 1999). Conforme Tabela 3, é possível observar que a farinha de trigo de grão inteiro apresenta menor resistência máxima, mas maior resistência a extensão quando comparada a farinha refinada, mostrando que esse tipo de massa tem menor capacidade de retenção de $\mathrm{CO}_{2}$ formando pela fermentação devido a menor formação da rede proteica pela proteína glutenina, proteína responsável por fazer ligações dissulfídricas intermoleculares e intramoleculares por causa do seu alto peso molecular. A análise do parâmetro A (energia), permite identificar ainda menor força da farinha de trigo de grão inteiro. Além disso, ainda utilizando os dados da Tabela 3, observa-se que a farinha de trigo de grão inteiro é menos extensível, isto é, se rompe mais facilmente quando esticada devido à proteína gliadina, responsável por fazer ligações dissulfídricas intramoleculares por causa do seu baixo peso molecular.

\subsection{Características das massas frescas tipo Spaguetthi}

As formulações dos espaguetes cru, cozido e a água de cozimento podem ser visualizados na Figura 1 e pode-se ver que a estrutura das massas foi melhorada com a adição de inhame, mostrando que foi possível obter massas de T. aestivum com $51 \%$ de FIG e sem ovos.

Figura 1. Fotografia das quatro formulações (M0, M1, M2 e M3) de massa fresca (a), massa cozida (b) e da presença de sólidos na água de cozimento (c), variando o teor de farinha de inhame, nos níveis de $0,5,10$ e $15 \%$ de substituição por farinha de trigo refinada.

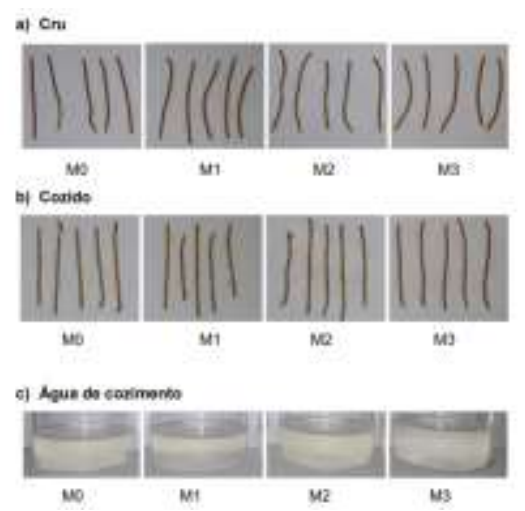

Fonte: Autores.

Conforme pode ser observado na Figura 1, a adição de farinha inhame substituindo a farinha de trigo branco na formulação das massas, acarretou em massas mais claras. M3 foi a que se apresentou mais clara à olho nu e isso foi comprovado a partir da leitura de cor, conforme dados apresentados na Tabela 4. 
Tabela 4. Parâmetros de cor para as massas crua e cozidas,

\begin{tabular}{ccccccc}
\hline \multirow{2}{*}{ Tratamentos } & \multicolumn{3}{c}{ Massa crua } & \multicolumn{3}{c}{ Massa cozida } \\
\cline { 2 - 6 } & L* & $\mathbf{a}^{*}$ & $\mathbf{b}^{*}$ & $\mathbf{L}^{*}$ & $\mathbf{a}^{*}$ & $\mathbf{b}^{*}$ \\
\hline M0 & $44,51 \pm 0,5 \mathrm{c}$ & $8,55 \pm 0,1 \mathrm{a}$ & $20,75 \pm 0,2 \mathrm{a}$ & $40,26 \pm 0,1 \mathrm{c}$ & $9,54 \pm 0,2 \mathrm{a}$ & $20,97 \pm 0,1 \mathrm{a}$ \\
M1 & $45,77 \pm 0,1 \mathrm{c}$ & $8,13 \pm 0,1 \mathrm{~b}$ & $19,82 \pm 0,2 \mathrm{a}$ & $41,99 \pm 0,1 \mathrm{~b}$ & $8,45 \pm 0,1 \mathrm{~b}$ & $19,89 \pm 0,1 \mathrm{~b}$ \\
M2 & $45,44 \pm 0,1 \mathrm{~b}$ & $7,97 \pm 0,1 \mathrm{c}$ & $19,5 \pm 0,1 \mathrm{a}$ & $42,01 \pm 0,2 \mathrm{~b}$ & $8,38 \pm 0,2 \mathrm{~b}$ & $19,44 \pm 0,2 \mathrm{~b}$ \\
M3 & $46,11 \pm 0,2 \mathrm{a}$ & $7,8 \pm 0,1 \mathrm{c}$ & $16,61 \pm 0,1 \mathrm{~b}$ & $43,72 \pm 0,1 \mathrm{a}$ & $7,69 \pm 0,1 \mathrm{c}$ & $18,46 \pm 0,2 \mathrm{c}$
\end{tabular}

Os dados são apresentados como média \pm desvio padrão. ${ }^{\mathrm{a}-\mathrm{c}}$ letras iguais na mesma coluna não diferem significativamente $(\mathrm{p}$-valor $>0,05)$ pelo teste de Duncan. Fonte: Autores.

Conforme a Figura 1, M2 e M3 foram as que apresentaram águas mais turvas após o cozimento da massa, o que pode ser confirmado através da análise de sólidos na água que tem seus resultados apresentados na tabela 4.É possível observar que a substituição de até $10 \%$ de farinha de inhame não afetou significativamente a umidade das massas M1 e M2 em relação ao controle. A formulação M3, que apresenta a maior porcentagem de substituição de farinha de inhame foi a que apresentou menor umidade e se diferiu da formulação controle significativamente. Segundo Wieser (2007) este fato pode ser por diminuir a quantidade de farinha de trigo refinada e, consequentemente, houve a diluição das proteínas formadoras do glúten, que proporciona as características físicas e reológicas de plasticidade, viscosidade e elasticidade importantes para a massa. Em relação à análise de firmezaa adição de farinha de inhame nas massas ocasionou em uma maior dureza das mesmas, tanto na massa crua, quanto cozida. Na massa crua, M1 e M2 não apresentaram diferenças significativas entre si, apresentando valores médios de 5,16 e 5,63 N, respectivamente no quesito força para cortar. Já na massa cozida, M2 não apresentou diferenças significativas em relação à M1 e M3. Comparando a massa crua com a cozida, o cozimento fez com que as massas ficassem mais macias, diminuindo o pico de força e o trabalho total para cortar.

Em relação ao rendimento, apenas M2 não apresentou diferenças significativas em relação à massa controle apesar de também se assemelhar à M3, enquanto M1 e M3 apresentaram tal diferença. A adição de farinha de inhame teve como consequência uma diminuição do rendimento das massas. Isso pode ser explicado igualmente à umidade das massas, isto é, com a diminuição da quantidade de farinha de trigo refinada, há uma diminuição do glúten que é constituído por uma massa viscoelástica tridimensional que ocasiona uma massa com menor absorção de água e que, portanto, apresenta um menor rendimento.

A respeito da análise de sólidos na água, apesar de todas as formulações se diferirem do controle, não apresentaram uma constância para esse parâmetro. Em M1, foi observada uma diminuição significativa de perda de sólidos, indicando que esta concentração é a mais adequada para uso nas massas contendo FIT. Já as substituições de 10 e $15 \%$ houve um aumento significativo nesse parâmetro. Isso pode ter ocorrido devido ao grau de degradação do grânulo de amido, ou seja, a somatória dos efeitos de gelatinização, dextrinização e consequente solubilização(Leonel et al., 2006). Uma grande substituição por farinha de inhame impacta na perda de sólidos, pois com uma menor quantidade de farinha de trigo, consequentemente há uma menor quantidade de proteínas formadoras de glúten que formam a rede viscoelástica tridimensional que mantém os nutrientes na massa. Assim o aumento da substituição por farinha de inhame há diminuição da formação de rede de glúten, e desse modo uma maior perda de sólidos.

A cor da massa integral constitui um fator muito importante para sua comercialização. No sistema CIEL*a*b*, $\mathrm{L}^{*}$ 
representa os valores para luminosidade (preto 0/branco 100), +a representa o vermelho, -a o verde, +b o amarelo e o -b o azul, em um plano cartesiano. No caso deste estudo, foi possível observar que o aumento da porcentagem de substituição de farinha de trigo por farinha de inhame, ocasionou em massas mais claras como pode ser observado pelo parâmetro L apresentado na Tabela 4.

No quesito cor, para a massa crua todas as massas se diferiram significativamente da massa controle em todos os parâmetros (L, a* e b*). M1 e M2 apresentaram diferença significativa entre si apenas no parâmetro b*, se assemelhado nos demais parâmetros ( $\left(\mathrm{e} \mathrm{a} \mathrm{a}^{*}\right.$ ), enquanto $\mathrm{M} 3$ apresentou diferenças significativas em todos os parâmetros em relação às demais massas. Em relação à massa cozida, todas as massas apresentaram diferenças significativas em relação à massa controle. Nos parâmetros L* e b* as massas M1, M2 e M3 não apresentaram diferenças significativas entre si, e em relação ao parâmetro a*, M2 não se diferiu significativamente de M1 e M3 apesar dessas últimas terem apresentado diferença significativa entre si nesse parâmetro.

Quanto à diferença de cor, Tiwari et al. (2008) classificou analiticamente as diferenças perceptíveis na cor em: muito distintas, distintas e pouco distintas, quando o valor de $\Delta \mathrm{E}$ for superior a 3,0, entre 1,5 e 3,0, e inferior a 1,5, respectivamente. De acordo com esta classificação, pode-se afirmar que para a massa crua houve uma variação distinta na cor para M1 e M2 comparando-se com a massa controle e uma variação muito distinta para M3. Para a massa cozida, todas a massas apresentaram variações distintas comparadas a massa controle.

Na Figura 2 estão os resultados das análises de Fenólicos Totais, ABTS e DPPH.Para as análises de capacidade antioxidante, a partir de análise estatística, a massa escolhida (M2) não apresentou diferenças significativas quando comparada com a massa controle, assim a substituição de farinha de trigo por farinha de inhame não afetou a capacidade antioxidante do produto final. Isso pode ser explicado pela alta influência que a farinha de grão inteiro de trigo teve sobre os resultados obtidos, que por sua vez não sofreram grande influência da substituição de $10 \%$ da farinha de trigo pela farinha de inhame. Em relação ao grão de trigo, no gérmen e farelo se encontram diversos componentes promotores de saúde, como por exemplo, antioxidantes naturais. Produtos obtidos a partir de farinha de trigo de grão inteiro têm evidentes efeitos à saúde quando comparados aos produtos que utilizam farinhas com apenas a parte interna do grão (Hirawan et al., 2010).

Pesquisas recentes mostram que os efeitos benéficos dos grãos inteiros não são atribuídos somente às fibras, mas também a outros compostos biologicamente ativos, principalmente aos antioxidantes. A capacidade antioxidante de produtos de grão inteiro é relativamente alta, sendo semelhante, e muitas vezes superior, ao de frutas ou de vegetais (Costabile et al., 2008; Hirawan et al., 2010). O consumo de alimentos de grãos inteiros está associado com a redução do risco de diversos tipos de doenças como cardiovasculares, diabetes tipo 2, obesidade e câncer(Hirawan et al., 2010). Essa redução do risco de doenças é explicada pela composição dos grãos integrais, que contém fitoquímicos exclusivos (Bunzel et al., 2001). Os grupos de fitoquímicos mais importantes encontrados nos grãos integrais são compostos fenólicos, carotenoides, vitamina E, ligninas, beta glucanas e inulina (Liu, 2007), que exercem função antioxidante prevenindo ou retardando danos oxidativos ao organismo, reduzindo o risco das doenças citadas acima (Arts \& Hollman, 2005; Kris-Etherton et al., 2002; Slavin, 2003). Os fitoquímicos combatem o stress oxidativo no organismo, ajudando a manter o balanço entre oxidantes e antioxidantes. Um desbalanço causado pela superprodução de oxidantes leva ao stress oxidativo, resultando em danos as moléculas do corpo. Tais danos aumentam o risco de doenças degenerativas como câncer e as cardiovasculares. Os antioxidantes reduzem os danos oxidativos das moléculas (Adom \& Liu, 2002).

A funcionalidade do inhame atribui-se à presença de fitoquímicos como carotenoides, compostos fenólicos e outros compostos bioativos os quais possuem a capacidade de neutralizar tais radicais livres no organismo, auxiliando desta forma na proteção de células e tecidos contra o estresse oxidativo, diminuindo o risco de doenças crônicas como doenças cardiovasculares, câncer ou doenças neurodegenerativas(Koh \& Mitchell, 2008). Apesar de tal funcionalidade, neste trabalho a adição de farinha 
de inhame não afetou na capacidade antioxidante da massa tipo Spaguetthi.

$\mathrm{Na}$ análise de fenólicos totais, M2 apresentou valor mais baixo quando comparado ao controle. Uma explicação para isso é que embora o método de Folin-Ciocalteau seja o método mais utilizado para quantificação de compostos fenólicos, o reagente Folin-Ciocalteau pode interagir com outros compostos não fenólicos o que pode levar a resultados superestimados de fenóis totais. Desta forma, alguns autores sugerem um passo adicional na análise de fenóis totais. Entretanto, esse composto apresenta menor potencial antioxidante no modelo DPPH que os compostos fenólicos, conforme relatado por quantidade extensiva de artigos. De um modo geral, a correlação entre fenóis totais e atividade antioxidante relatada na literatura é contraditória. Enquanto alguns autores observaram uma alta correlação; outros não observam correlação direta. Estudos indicam que a correlação entre fenóis totais e a capacidade antioxidante pode depender do método escolhido e também das características hidrofóbicas ou hidrofílicas do sistema teste e dos antioxidantes testados (Roesler et al., 2007).

De acordo com os resultados obtidos para as três análises, o espaguete M2, não diferiu significativamente do M0. A adição de inhame manteve a mesma a atividade antioxidante e não interagiu negativamente com os compostos antioxidantes da FIT. Assim o inhame mostra grande importância no seu uso por não prejudicar a qualidade funcional do produto final e apresentar grande potencial para promover a agronegócio e para aumentar a produção de massas alimentícias brasileiras completamente vegetarianas.

\section{Conclusão}

Pode-se concluir que massas contendo a formulação 51\% de farinha de trigo integral, $10 \%$ de farinha de inhame e 39\% de farinha refinada de trigo podem ser viáveis para a dieta do brasileiro e ao mesmo tempo promover futuras aplicações da farinha de inhame com finalidade de valorização desta cultura para o agronegócio.

\section{Agradecimentos}

Os autores agradecem a Coordenação de Aperfeiçoamento de Pessoal de Nivel Superior (CAPES) pelo apoio financeiro (código 001).

\section{Referências}

AACCI. (2010). Approved Methods of Analysis. AACC International.

Adom, K. K., \& Liu, R. H. (2002). Antioxidant Activity of Grains. Journal of Agricultural and Food Chemistry, 50(21), 6182-6187. https://doi.org/10.1021/jf0205099

Amorim, A. L. B. de, Ribeiro Junior, J. R. S., \& Bandoni, D. H. (2020). Programa Nacional de Alimentação Escolar: estratégias para enfrentar a insegurança alimentar durante e após a COVID-19. Revista de Administração Pública, 54(4), 1134-1145. https://doi.org/10.1590/0034-761220200349

Arts, I. C., \& Hollman, P. C. (2005). Polyphenols and disease risk in epidemiologic studies. The American Journal of Clinical Nutrition, 81(1), 317S-325S. https://doi.org/10.1093/ajen/81.1.317S

Brand-Williams, W., Cuvelier, M. E., \& Berset, C. (1995). Use of a free radical method to evaluate antioxidant activity. LWT - Food Science and Technology, 28(1), 25-30. https://doi.org/10.1016/S0023-6438(95)80008-5

Brasil, Ministério da Agricultura, P. e do A. (2005). Regulamento Técnico de Identidade e Qualidade da Farinha de Trigo (p. 2).

Brasil, Ministério da Agricultura, P. e do A. (2010). Instrução Normativa $n^{\circ}$ 38, de 30 de Novembro de 2010.

Bunzel, M., Ralph, J., Marita, J. M., Hatfield, R. D., \& Steinhart, H. (2001). Diferulates as structural components in soluble and insoluble cereal dietary fibre. Journal of the Science of Food and Agriculture, 81(7), 653-660. https://doi.org/10.1002/jsfa.861

Costabile, A., Klinder, A., Fava, F., Napolitano, A., Fogliano, V., Leonard, C., Gibson, G. R., \& Tuohy, K. M. (2008). Whole-grain wheat breakfast cereal has a prebiotic effect on the human gut microbiota: a double-blind, placebo-controlled, crossover study. British Journal of Nutrition, 99(1), 110-120. https://doi.org/10.1017/S0007114507793923

Demir, B., \& Bilgiçli, N. (2020). Utilization of quinoa flour (Chenopodium quinoa Willd.) in gluten-free pasta formulation: Effects on nutritional and sensory properties. Food Science and Technology International, 1-9. https://doi.org/10.1177/1082013220940092 
Donado-Pestana, C. M., Salgado, J. M., de Oliveira Rios, A., dos Santos, P. R., \& Jablonski, A. (2012). Stability of Carotenoids, Total Phenolics and In Vitro Antioxidant Capacity in the Thermal Processing of Orange-Fleshed Sweet Potato (Ipomoea batatas Lam.) Cultivars Grown in Brazil. Plant Foods for Human Nutrition, 67(3), 262-270. https://doi.org/10.1007/s11130-012-0298-9

França, F. C. O., Mendes, A. C. R., Aandrade, I. S., Ribeiro, G. S., \& Pinheiro, I. (2002). Mudanças dos hábitos alimentares provocados pela industrialização e o impacto sobre a saúde do brasileiro. Anais Do I Seminário Alimentação e Cultura Na Bahia, 1-7.

Hirawan, R., Ser, W. Y., Arntfield, S. D., \& Beta, T. (2010). Antioxidant properties of commercial, regular- and whole-wheat spaghetti. Food Chemistry, 119(1), 258-264. https://doi.org/10.1016/j.foodchem.2009.06.022

Hobbs, J. E. (2020). Food supply chains during the COVID-19 pandemic. Canadian Journal of Agricultural Economics, 68(2), 171-176. https://doi.org/10.1111/cjag.12237

Hoover, E. (2020). Native food systems impacted by COVID. Agriculture and Human Values. https://doi.org/10.1007/s10460-020-10089-7

Koh, E., \& Mitchell, A. E. (2008). Trends in the analysis of phytochemicals. In M. S. Meskin, W. R. Bidlack, \& R. E. Randolph (Eds.), Flavonoids and Carotenoids (pp. 39-76).

Kris-Etherton, P. M., Hecker, K. D., Bonanome, A., Coval, S. M., Binkoski, A. E., Hilpert, K. F., Griel, A. E., \& Etherton, T. D. (2002). Bioactive compounds in foods: their role in the prevention of cardiovascular disease and cancer. The American Journal of Medicine, 113(9), 71-88. https://doi.org/10.1016/S00029343(01)00995-0

Laborde, D., Martin, W., Swinnen, J., \& Vos, R. (2020). COVID-19 risks to global food security. Science, 369(6503), 500-502. https://doi.org/10.1126/science.abc4765

Leonel, M., Mischan, M. M., Pinho, S. Z. de, Iaturo, R. A., \& Duarte Filho, J. (2006). Efeitos de parâmetros de extrusão nas propriedades físicas de produtos expandidos de inhame. Ciência e Tecnologia de Alimentos, 26(2), 459-464. https://doi.org/10.1590/S0101-20612006000200033

Liu, R. H. (2007). Whole grain phytochemicals and health. Journal of Cereal Science, 46(3), 207-219. https://doi.org/10.1016/j.jcs.2007.06.010

Monteiro, P. L., Santos, A. F. B. da S., Pires, C. R. F., Pereira, A. S., Kato, H. C. A., Sousa, D. N. de, \& Fogaça, F. H. dos S. (2020). Enriquecimento de massa fresca tipo talharim com farinha de marisco (Anomalocardia brasiliana). Research, Society and Development, 9(8), e336985662. https://doi.org/10.33448/rsdv9i8.5662

Pizzinato, A. (1999). Qualidade da farinha de trigo: conceitos, fatores determinantes, parâmetros de avaliação e controle (Primeira E). ITAL.

Quinaud, B. E. R., Monteiro, P. L., Pires, C. R. F., Santos, V. F. dos, Kato, H. C. A., \& Sousa, D. N. de. (2020). Elaboração e caracterização nutricional de massa alimentícia enriquecida com resíduo de soja. Research, Society and Development, 9(7), e718974724. https://doi.org/10.33448/rsd-v9i7.4724

Re, R., Pellegrini, N., Proteggente, A., Pannala, A., Yang, M., \& Rice-Evans, C. (1999). Antioxidant activity applying an improved ABTS radical cation decolorization assay. Free Radical Biology and Medicine, 26(9-10), 1231-1237. https://doi.org/10.1016/S0891-5849(98)00315-3

Roesler, R., Catharino, R. R., Malta, L. G., Eberlin, M. N., \& Pastore, G. (2007). Antioxidant activity of Annona crassiflora: Characterization of major components by electrospray ionization mass spectrometry. Food Chemistry, 104(3), 1048-1054. https://doi.org/10.1016/j.foodchem.2007.01.017

Schneider, S., Cassol, A., Leonardi, A., \& Marinho, M. de M. (2020). Os efeitos da pandemia da Covid-19 sobre o agronegócio e a alimentação. Estudos Avançados, 34(100), 167-188. https://doi.org/10.1590/s0103-4014.2020.34100.011

Siqueira, M. V. B. M. (2011). Yam: a neglected and underutilized crop in Brazil. Horticultura Brasileira, 29(1), 16-20. https://doi.org/10.1590/S010205362011000100003

Slavin, J. (2003). Why whole grains are protective: biological mechanisms. Proceedings of the Nutrition Society, 62(1), 129-134. https://doi.org/10.1079/PNS2002221

Tiwari, B. K., Muthukumarappan, K., O’Donnell, C. P., Chenchaiah, M., \& Cullen, P. J. (2008). Effect of ozonation on the rheological and colour characteristics of hydrocolloid dispersions. Food Research International, 41(10), 1035-1043. https://doi.org/10.1016/j.foodres.2008.07.011

Vimercati, W. C., Macedo, L. L., Araújo, C. da S., Maradini Filho, A. M., Saraiva, S. H., \& Teixeira, L. J. Q. (2020). Effect of storage time and packaging on cooking quality and physicochemical properties of pasta with added nontraditional ingredients. Journal of Food Processing and Preservation, 44(9), 1-12. https://doi.org/10.1111/jfpp.14637

Wieser, H. (2007). Chemistry of gluten proteins. Food Microbiology, 24(2), 115-119. https://doi.org/10.1016/j.fm.2006.07.004 